\title{
Personalized and dynamic antibiograms-an exploration in seven infectious syndromes
}

Michelle J. Iandiorio ${ }^{1}$, Jane C. Fazio ${ }^{2}$, Prakasha Kempaiah ${ }^{3 *}$, Ravi Darvasula ${ }^{3}$, Marc H. V. van Regenmortel ${ }^{4}$, Ariel L. Rivas ${ }^{*}$

${ }^{1}$ Division of Infectious Diseases, School of Medicine, University of New Mexico, Albuquerque, NM, USA

${ }^{2}$ Department of Pulmonary and Critical Care Medicine, University of California Los Angeles, Torrance, CA, USA

${ }^{3}$ Department of Infectious Diseases, Mayo Clinic, Jacksonville, Florida, USA

${ }^{4}$ University of Vienna, Austria; and Higher School of Biotechnology, University of Strasbourg, France

${ }^{5}$ Center for Global Health-Division of Infectious Diseases, School of Medicine, University of New Mexico, Albuquerque, NM, USA

* Correspondence: alrivas@unm.edu

* Co-Corresponding author: Kempaiah.Prakasha@ mayo.edu

Keywords: personalized prognostics, antibiotics, infection, pathogen-immunologicalantibiotic interaction, pattern recognition-based visualization 


\section{ABSTRACT}

To prevent antimicrobial resistance and inform better, antibiograms should distinguish different biomedical situations. It is also desirable that new antibiograms provide in vivo, temporal, and patient-specific immunological information. Here, the informative ability of a pattern recognition-based method was explored with data collected from patients that experienced seven infectious syndromes (pneumonia, endocarditis, tuberculosis, syphilis, as well as skin and soft tissue, intra-abdominal, and/or urinary tract infections associated with meningitis). Interactions among seven dimensions (7D) were investigated: (i) space, (ii) time, (iii) temporal data directionality, (iv) immunological multicellularity, (v) antibiotics, (vi) immunomodulation, and (vii) personalized data. Omissions and ambiguity (confounding different biological situations) occurred when static metrics were used in isolation, such as leukocyte percentages. In contrast, hidden information was uncovered when complexity and dynamics were assessed. The 7D approach grouped together observations that displayed similar immune profiles and identified antibiotics that modulated specific leukocytes. For instance, in tuberculosis, blood monocytes were modulated by isoniazid-related antimicrobials. In spite of the diverse syndromes analyzed, this proof-of-concept discriminated. It is suggested that the simultaneously exploration of numerous dimensions associated with complexity may be biologically interpretable, prevent ambiguity, promote research, expand machine learning-oriented methods, and support personalized medicine.

\section{INTRODUCTION}

New methods have been recently requested by physicians. Such calls respond to the 'reproducibility crisis' of clinical research, characterized by up to $90 \%$ of irreproducible 
studies. ${ }^{1}$ Numerous factors seem to cause this problem, which are not limited to statistical errors. ${ }^{2}$ They also include reductionist practices, e.g. (i) the 'streetlight' effect (measuring what is easily measured, but not biomedically relevant), (ii) dichotomous and static methods applied to biomedical conditions that may be dynamic and polychotomous; and (iii) research designs that ignore co-morbidities and interactions. ${ }^{1-7}$

Because the unit of interest, in clinical medicine, is one patient (not a plurality, as in population medicine), neither averages nor linear models apply and, consequently, it cannot to be established whether one specific patient will benefit from a specific intervention. ${ }^{2,8,9}$ Personalized medicine also requires novel cognitive approaches. The current emphasis (promoted by 'evidence-based' medical practices) expects clinicians to reason from the general (population average) to the particular (patient). However, the history of each patient (including multi-morbidities and polypharmacy) also needs be considered. ${ }^{10,11}$

To address these issues, non-reductionist analyses of biomedical complexity and dynamics are needed. Because two patients receiving the same diagnosis may differ in outcomes, prognosis should also be explored. ${ }^{2,4,9,12,13}$ Future methods should not utilize a single type of data but integrate theory with data that includes spatial-temporal dimensions. ${ }^{14-}$ ${ }^{17}$ In addition, 'one person trials' may be considered, which may investigate immunological multicellularity -a critical component in responses against infections. ${ }^{18-20}$

Antimicrobial resistance is one example of the medical problems non-reductionist approaches should address. New strategies could go beyond the classic focus on antibioticpathogen relationships and also interrogate the immune response of the host. ${ }^{21,22}$

Research on immunomodulation has shown, for example, that norfloxacin promotes neutrophils, while linezolid suppresses phagocytosis, both in vivo and in vitro. ${ }^{23,24}$ Similar 
studies have shown that macrolides suppress bacterial infection of the lungs and reduce inflammation. ${ }^{25}$ Long-acting macrolide antibiotics, such as azithromycin, can protect even if given intermittently. ${ }^{26}$ To prevent multi-drug antimicrobial resistance, combinations of antibiotics and antibodies have been proposed. ${ }^{27}$

Studies that investigate immunological multicellularity and/or immunological and antibiotic interactions matter clinically because, in many infections, empirical antibiotic treatments are prescribed when the identity of the pathogen is unknown. For instance, in pneumonia, pathogens may be isolated in only one third of the cases. ${ }^{28}$ Thus, earlier and in vivo assessments are needed to evaluate the efficacy of empirical treatments.

Investigations on antibiotic-immunological interactions could also shed light on the pathogenesis of major diseases and, consequently, influence vaccine development. For instance, very little is known on the pathogenesis of tuberculosis -a disease that requires better vaccines because current ones have only a $30 \%$ efficacy. ${ }^{29}, 30$ In particular, immunological-antibiotic interactions should elucidate whether antibiotics foster or inhibit the functions of immune cells..$^{31,32}$

Since 1947, antibiotics have been investigated with in vitro tests (antibiograms or antibiotic sensitivity). Such tests have several limitations, including absence of dynamic perspectives, which only in vivo studies can provide. ${ }^{33-35}$ Because they lack personalized information, these tests inherently support the 'one dose fits all' paradigm. ${ }^{36}$

While the problems associated with reductionism have been abundantly documented over two decades ${ }^{37-39}$, very few solutions have been proposed. Here an approach meant to ameliorate reductionism-related problems is advanced.

To materialize this pursuit, novel tests used in infectious diseases should demonstrate 
that they do not generate ambiguous results. Ambiguity refers to lack of decision-making not due to lack of data but because the data do not discriminate. ${ }^{40}$ Health trajectory (also known as temporal data directionality) is one strategy that may prevent ambiguity. ${ }^{41}$ Trajectory differs from classic measurements of time: by using arrows that connect pairs of consecutive observations, the directionality of temporal data is unmasked, providing a new level of information. Health trajectory is a person-centered metric that describes the 'flight path of an object', informing on the direction and/or speed of a health change. While trajectory has been studied with aggregate data, the complex dynamics of health trajectories have not been explored at personalized bases. ${ }^{42,43}$ While trajectory has been investigated in infections, earlier studies did not assess antibiotics. ${ }^{40,44}$

Data collected from patients affected by seven infectious syndromes were explored. They included endocarditis, pneumonia, tuberculosis, syphilis, as well as intra-abdominal, skin and soft tissue, and/or urinary tract infections associated with meningitis. The selection of syndromes was based on their prevalence, in-hospital mortality, and/or recent trends. For example, in the US, infective endocarditis results in prolonged hospitalization and is associated with $20 \%$ in-hospital mortality. ${ }^{45}$ Worldwide, pneumonia causes 2-3 million annual deaths and, in the US, approximately 100,000 in-hospital annual deaths. ${ }^{46,47}$ Intraabdominal infections may result in up to $36 \%$ mortality. ${ }^{48}$ While rarely fatal, the prevalence of skin and soft tissue infections is rapidly increasing in the US. ${ }^{49}$

Seven dimensions were explored: (i) three-dimensional (3D) space, (ii) time, (iii) trajectory, (iv) multicellularity, (v) antibiotics, (vi) immunological-antibiotic interactions, and (vii) patient-specific information. The goal of this study was to elucidate (i) whether ambiguity was a rare phenomenon, and (ii) if not, whether a non-reductionist approach could 
prevent ambiguity, discriminate, and/or inform.

\section{MATERIALS AND METHODS}

$\underline{\text { Data }}$

Seventy longitudinal observations collected from nine adults diagnosed with infective endocarditis, pneumonia, tuberculosis, syphilis, intra-abdominal, skin and soft tissue, and/or urinary tract infections associated with meningitis were analyzed. Day 0 indicated the first consultation or the date of hospitalization.

This study was conducted as described in Protocol \#13-463, which was approved by the Institutional Research Protection Office committee of the Health Sciences Center, University of New Mexico on June 23, 2016 (protocol titled 'Small Dataset-Based Discrimination of Infectious Disease Pattern', Dr. M Iandiorio, PI). This protocol protects the identity of the patients investigated. The data were anonymized by a double-blind process in which the treating clinician does not participate in the analysis of the data and the data analyst does not receive any information that could identify the patients. Because this protocol allows the retrieval and analysis of clinical data from historical clinical records without a previous review, no waiver was requested and no decision from the competent authority was required in advance for any one study. The identification numbers reported in this study were created by the analyst in order to perform the analysis - they do not / cannot identify any person.

\section{Assessment of biomedical validity}

Construct, internal, and external validity were investigated. Statistical validity was not determined because such a research goal is only justified after the other types of validity 
are shown to be defensible. Because external validity depends on or follows construct and internal validities, demonstration of external validity was emphasized. ${ }^{50}$

This study was designed to determine whether the data patterns, if any, were robust to both patient and syndrome variability. To that end, a dataset was constructed to include: (i) at least five infectious syndromes and nine patients; (ii) at least two infectious syndromes would be explored with data from two patients, (iii) at least one co-morbidity would be investigated; (iv) at least one patient was not treated with antibiotics; and (v) in at least one patient, longitudinal observations would not start with antibiotic treatments so pre-/posttreatment data could be investigated. External validity was regarded to be plausible when at least one multicellular interaction (e.g., the lymphocyte \% over the monocyte \% or L/M ratio) distinguished non-overlapping data subsets, patients, trajectories, temporal phases and/or infectious syndromes.

\section{$\underline{\text { Analyses }}$}

Distinct data patterns were identified as described elsewhere. ${ }^{4,13,40,44}$ Partitioning into data groups that, internally, exhibited similar immune profiles, was conducted using a proprietary algorithm (US patent 10,429,389; 2019). Two- and three-dimensional (2D and 3D) plots were created with a commercial package (Minitab Inc., State College, PA, USA).

\section{RESULTS}

Detection and prevention of ambiguity. Analyses of individual cell types were ambiguous. For example, a patient diagnosed with endocarditis exhibited similar leukocyte percentages even when samples were collected 29 days apart (Figs. 1 A, B). Because leukocyte 
percentages do not explore interactions, further analyses measured dimensionless indicators (DIs) designed to capture complexity. When time was investigated, DIs revealed numerous changes in trajectory, which differentiated two subsets that exhibited: (i) 'left-to-right', and (ii) 'right-to-left' flows, respectively (Figs. 1 C, D). Trajectory-based assessments showed non-overlapping data intervals of interpretable variables: when the lymphocyte percentage was divided over the monocyte percentage (the L/M ratio), two subsets were distinguished (Fig. 1 E). When spatial patterns and multicellular interactions were analyzed, the 7D method differentiated (i) two data subsets, as well as (ii) three data points that, previously, could not be separated (Figs. $1 \mathrm{~F}, \mathrm{G}$ ). Complex multicellular indices -the L/M ratio and an indicator of greater complexity (e.g., the $[\mathrm{L} / \mathrm{M}] /[\mathrm{N} / \mathrm{L}]$ ratio)- discriminated more or better than leukocyte percentages (Figs. $1 \mathrm{~B}, \mathrm{G})$.

Data collected from another patient diagnosed with endocarditis and treated with antibiotics highlighted the dynamics of the immunological-antibiotic interactions: differentiating two temporal phases, vancomycin and cefazolin both promoted and inhibited immune responses (SI Figs. $1 \mathrm{~A}-\mathrm{H}$ ). The discriminant ability of the L/M ratio was, again, documented: non-overlapping data intervals separated an earlier from a later data subset, even when the M percentage exhibited overlapping intervals (SI Figs. 1F, H).

Short-term ambiguity and real-time antibiotic monitoring. Skin and soft tissue infections (SSTI) also revealed ambiguity when investigated with isolated variables (Figs. 2 A-D). When the neutrophil/monocyte $(\mathrm{N} / \mathrm{M})$ and the lymphocyte/monocyte $(\mathrm{L} / \mathrm{M})$ ratios were explored, data points collected at the third and fourth day were assigned to separate clusters (Fig. 2 E). In contrast, data points recorded nine days apart were clustered together (Fig. 2 E). 
When trajectory was considered, the $\mathrm{M}$ percentage revealed two data subsets orthogonal to one another, which exhibited different directionality (Fig. 2F). While the L and N percentages also displayed two subsets, they were not perpendicular to one another (Figs. 2 $\mathrm{G}, \mathrm{H})$. Because only the $\mathrm{M}$ percentage changed directionality after antibiotic treatment, it was concluded that ceftriaxone and vancomycin immunomodulated monocytes (Fig. 2 I).

Pattern reproducibility. A second SSTI case demonstrated that ambiguity may occur even when temporal data directionality is measured (SI, Figs. 2 A-H). While uni-dimensional (1D) analyses of percentages could be ambiguous (SI, Figs. 2 E, F), 3D analyses of complex interactions discriminated (SI Fig. 2G).

The N/M ratio was demonstrated to be a well conserved function: it informed in two SSTI patients (Figs. 2 and SI 2). Within one day, the complex [N/M]/[L/M] ratio indicated recovery after nafcillin was administered (SI, Fig. $2 \mathrm{H}$ ).

Ambiguity was also found in pneumonia: two data points were ambiguous when the neutrophil and monocyte percentages were evaluated (Fig. 3 A, B). In contrast, the analysis of complexity, dynamics, and trajectory identified two non-overlapping data subsets (Figs. 3 C-F). The pattern recognition/based method discriminated earlier (at day 9, when the N/L ratio was used [Fig. $3 \mathrm{G}]$ ) than when the N\% was measured (Fig. 3 A) as opposed to day 18 and indicated that recovery was not initiated by any one antibiotic (Fig. $3 \mathrm{H}$ ).

Multidimensional analysis discriminated two subsets of intra-abdominal infections (Figs. 4 A-E). In contrast, the analysis of individual cell types failed to distinguish data subsets (Figs. 4 F-H). Ceftriaxone and metronidazole appeared to modulate a complex function characterized by the $[\mathrm{L} / \mathrm{M}] /[\mathrm{N} / \mathrm{L}]$ ratio (Fig. $4 \mathrm{E}$ ). 
Redundancy and immune-modulation in tuberculosis. Discrimination did not depend on any one dimensionless indicator: three different group of DIs (the $\mathrm{L} / \mathrm{M},[\mathrm{L} / \mathrm{N}] /[\mathrm{M} / \mathrm{N}]$, and $[\mathrm{L} / \mathrm{M}] /[\mathrm{M} / \mathrm{L}]$ ratios) differentiated two 3D data subsets (Figs. 5A-D). In contrast, leukocyte percentages did not discriminate even when tested in pairs (Figs. 5 E-G). Yet, when antibiotics were measured, both $3 \mathrm{D}$ and $2 \mathrm{D}$ analyses revealed that monocytes were modulated by the isoniazid-related antibiotics (Figs. $5 \mathrm{H}, \mathrm{I}$ ).

Ambiguity was also observed in neurosyphilis (boxes, SI, Figs. 3 A, B). When complexity and trajectory were measured in space/time, two data subsets were distinguished, which differed in both $\mathrm{L} / \mathrm{M}$ and $[\mathrm{L} / \mathrm{M}] /[\mathrm{M} / \mathrm{L}]$ ratio values (SI, Figs. $3 \mathrm{C}-\mathrm{E}$ ). When trajectory was assessed, these metrics distinguished three subsets (SI, Fig. 3 F). When antibiotics were considered, the 3 subsets were reconfigured, indicating that clindamycin, aztreonam and trimethoprim/sulfamethoxazole modulated a complex function characterized by the [L/M]/[M/L] ratio (SI, Fig. $3 \mathrm{G})$.

Feedback patterns in co-morbidities. Ambiguity was associated with co-morbidities (Fig. 6A). When space, time, immunological multicellularity, and trajectory were investigated, three temporal phases were observed, which revealed circular (feedback-like) data patterns (Figs. 6 B-E). When antibiotics were also investigated, amphotericin B was the only antifungal associated with all temporal phases (Fig. 6 F). When leukocytes were explored over time, a ' $\mathrm{V}$ ' shape pattern supported the notion that lymphocytes were modulated by amphotericin B (Figs. 6 G-I). 


\section{DISCUSSION}

Nine out of 9 assessments revealed various expressions of ambiguity. They were prevented and more or novel information was extracted when seven dimensions were investigated. Findings are discussed along methodological and clinical perspectives.

\section{Methodological considerations}

Ambiguity was observed in all patients. Given its ubiquity, it is suggested that ambiguity may contribute to the reported 'reproducibility crisis' of published research. ${ }^{1}$

Ambiguity is related to synergism and pleiotropy: the same structure (e.g., a cytokine or a cell) can perform many (and even opposite) functions, at different times. Monocytes/ macrophages illustrate how ambiguity occurs: they promote neutrophil activity at the beginning of the immune response and, a few days later -when the early inflammatory stage ends-, they destroy neutrophils. ${ }^{51}$ Therefore, a '10\% monocyte' value can be ambiguous because it can occur in different biomedical conditions or times, as shown in Fig. 3B.

Because infection-related data are, at least, four-dimensional, ambiguity is mathematically intractable. ${ }^{13,52,53}$ Any biomedical variable may have a very large number of combinations (if not infinity) when all dimensions are considered, i.e., for any value of 'width', there are many possible values of 'height', 'depth', and 'time.' Yet, ambiguity may disappear when context is added. ${ }^{53}$ Here contexts were explored considering (i) temporal interactions (the dynamics of immunological multicellularity with and without antibiotics) and (ii) other dimensions.

The information provided by the non-reductionist approach may result from the complexity and dynamics of multi-scalar and multicellular interactions. When changes occur 
at small temporal scales -e.g., molecular processes that take place at a nanosecond scale-, any study based on a larger scale (e.g., days) will miss such changes. ${ }^{54}$ These errors are prevented when temporal data directionality is measured: arrows pointing at different directions indicate changes. In addition, the simultaneous analysis of up to seven dimensions can generate richer information on multi-level, inter-dependent biological interactionss. ${ }^{55}$ While the analysis of complexity is not always informative, finding demonstrated that dynamics (longitudinal data on leukocytes and antibiotics) both informed and explained.

The 7D approach is compatible with classic statistics as well as machine (statistical) learning. ${ }^{56}$ Because current machine learning (ML) approaches provide correlational but not causal information, they are not explanatory and, consequently, their actual predictability (also known as overfitting) is rather poor. ${ }^{32,57} \mathrm{ML}$ is associated with big datasets, which assume static (stable) relationships and tend to use aggregate (not personalized) data. ${ }^{58}$

According to their transparency and interpretability, machine learning methods are categorized as 'black' or 'white box.' While black box models are not transparent, they have been reported to be highly informative when complexity is captured; yet, white box models are favored because they can be interpreted. ${ }^{59}$ Both ML versions share two aspects: (i) dependency on large numbers (a possible limitation when $n=1$ ), and (ii) linearity and reductionism, including the assumption that causes are independent, not interdependent. ${ }^{50}$

The complexity-oriented method differs from the two research traditions mentioned above: while new 'white box' approaches have recently been applied in machine learningrelated research on antibiotics, they are still influenced by linear models. ${ }^{57}$ In contrast, the non-reductionist approach discriminated regardless of any data distribution because it was based on 3D data shapes (patterns that do not depend on numerical cutoffs). Because 
biomedicine is complex, dynamic, non-linear, and composed of interdependent processes, the method here described can complement both black- and white-box approaches, countering the overfitting attributed to machine learning. ${ }^{60}$ This approach can also be applied with other dimensions, including molecular and genomic data.

\section{Clinical applications}

\section{Personalized medicine.}

The non-reductionist approach circumvents both the risks associated with ambiguity and the limitations of research designs that depend on population metrics, which tend to ignore co-morbidities. Because co-morbidities are associated with poly-pharmacy and exposure to diverse environments and lifestyles, patient-centered (not population-based) approaches are needed, followed by extensive evaluations, i.e., studies on external validity or generalizations. $^{61,62}$

While co-morbidity (two of more medical conditions diagnosed in the same person) has been reported in $23 \%$ of the US general population, and more than $60 \%$ of the population above 65 years of age ${ }^{63}$, randomized clinical trials (RCT) assume that only one medical condition exists. ${ }^{64}$ Yet, infectious and non-infectious syndromes -such as tuberculosis, human immunodeficiency virus, and malaria, as well as diabetes mellitus and tuberculosistend to yield worse outcomes and affect more people than when they act alone. ${ }^{65,66,67}$

Because up to $81.3 \%$ of RCT have excluded patients presenting with co-morbidities, the external validity of such designs is unknown. Because they assume that no interactions exist, RCT also lack construct validity. ${ }^{68,69}$ 
medRxiv preprint doi: https://doi.org/10.1101/2021.01.22.21249954; this version posted January 26, 2021. The copyright holder for this preprint (which was not certified by peer review) is the author/funder, who has granted medRxiv a license to display the preprint in perpetuity.

It is made available under a CC-BY-ND 4.0 International license .

\section{II- Pathogenesis- and vaccine development-related research}

As previously reported, the N/L ratio reached high levels in bacterial pneumonia. ${ }^{70} \mathrm{~A}$ remarkable decrease of this metric was noticed before treatment started (from $\sim 90$ to $\sim 15$ N/L values, Fig. 3G). This was a desirable outcome because, in pneumonia, mortality may follow a protracted inflammation, which may remain even after bacterial clearance. ${ }^{71}$

The observed isoniazid-related immunomodulation of monocytes (Fig. 5 I) may be of interest in vaccine development against tuberculosis. At least two factors may explain the poor efficacy of vaccines against tuberculosis ${ }^{31}$ : (i) evaluations based on aggregate data, which promote confounding because they cannot distinguish poor immunogens from poor responders; and (ii) evaluations that measure isolated structures (e.g., a specific cell type) but do not assess functions. In contrast, this study utilized personalized data to investigate multicellular interactions. Thus, the research design here described may investigate individual-level factors which, in tuberculosis, may influence vaccine efficacy. ${ }^{72}$

Antibiotic-leukocyte temporal interactions differed among leukocytes: a double linear process (first, decreasing; later, increasing) was observed between the M\% and time but the early linear relationship was not observed when either the L\% or N\% were investigated over time (Figs. 5 E-G). Hence, the evidence indicated modulation of monocytes: the M\% rapidly and linearly decreased in blood before isoniazid-related treatment was prescribed and only increased, also linearly, after that therapy was applied.

The findings reported in Fig. 5 also corroborated a study that related blood monocytes to ex vivo protection against tuberculosis. The same report attributed an informative role to the $\mathrm{L} / \mathrm{M}$ ratio. ${ }^{73}$ Because the $\mathrm{L} / \mathrm{M}$ ratio distinguished data subsets across five patients and syndromes (Figs. 1-5), its external validity was documented. ${ }^{50}$ 


\section{III - Antibiotic- and antibiogram-related applications}

Classic antibiograms (or antibiotic sensitivity tests) have six limitations. They include lack of (i) in vivo, (ii) dynamic, (iii) personalized, and (iv) immunological information, and also (v) delayed results and (vi) procedures that do not facilitate the real-time evaluation of therapies. $^{36}$

Furthermore, in vitro and in vivo systems are likely to differ, e.g., the concentration of iron is rather high in vitro but low in vivo ${ }^{74,75}$ Because antibiograms ignore dynamics and depend on growth inhibition, they cannot investigate antibiotic bactericidal activity in drugtolerant bacteria. ${ }^{76,77}$ Because these tests do not inform at personalized level, they cannot explore immunomodulation. Yet, the 7D approach may help to understand antimicrobial resistance. For instance, amoxicillin-resistant pneumococci and penicillin-resistant S. aureus may escape phagocytosis due to direct and indirect actions of these bacteria on neutrophils. ${ }^{78}$,

${ }^{79}$ It has been claimed that the first step toward new strategies against antimicrobial resistance is the development of new antibiograms, which should be personalized. ${ }^{80}$ Furthermore, the long turnaround (48-72 hours) of antibiograms promotes empirical antibiotic therapy (which may ineffective) and fosters antimicrobial resistance. ${ }^{80,81}$

Findings support the view that, when ambiguity is prevented, the six problems described above could be avoided. In addition, antimicrobial agent-associated immunomodulation could be investigated. The fact that amphotericin modulated lymphocytes in a co-morbidity case (Fig. $6 \mathrm{G}$ ) corroborated (with in vivo data) in vitro reports on the effect of this antibiotic on immunosuppressed patients affected by fungal infections. ${ }^{82,83}$ While in vivo synergism between amphotericin and linezolid has been 
reported in studies conducted with flies, to the best of our knowledge, this is the first study that reports in vivo, human-based evidence of synergic interactions involving amphothericin, linezolid, and flucytosine. ${ }^{84,85}$ Because numerous interactions may occur when antibiotic, antiviral, antifungal and/or antituberculosis drugs are prescribed, in vivo and personalized monitoring of therapies are needed. 86,87

In conclusion, findings supported the construct, internal, and external validity of a highly multi-dimensional method that, in vivo, prevents ambiguity, provides patientspecific (personalized) and immunologically explicit (white box) information on infection disease-related dynamics of antibiotic-mediated immuno-modulation. To determine its replicability, additional studies are recommended.

\section{Author contributions}

Conceived the study: AR, MR. Contributed data: MI and JF. Wrote the paper: AR, PK, and RD.

\section{Funding}

This research received no specific grant from any funding agency in the public, commercial, or not-for-profit sectors.

\section{Conflict of interest}

$\mathrm{AR}$ is a co-inventor of the algorithm used to recognize patterns (European Patent Office 2959295, US Patent 10,429,389 B2). 


\section{FIGURE LEGENDS}

Figure 1. Detection and prevention of ambiguity in endocarditis. Revealing ambiguity, three numerically similar observations were found at different time points (A, B). Over time, dimensionless indicators differentiated two data directionalities (trajectories): from 'left-toright' and from 'right-to-left' (C, D). Trajectory distinguished two data subsets, which displayed non-overlapping intervals of $\mathrm{L} / \mathrm{M}$ and $[\mathrm{L} / \mathrm{M}] /[\mathrm{M} / \mathrm{N}]$ ratios both when time was not and was considered $(\mathbf{E}, \mathbf{F})$. When space, time, and multicellularity were analyzed, the three data points previously regarded as ambiguous were clearly differentiated $(\mathbf{G})$.

Figure 2. Detection and prevention of ambiguity and antibiotic modulation of monocytes. Ambiguity was also found in a case of skin/soft tissue infections $(\mathbf{A}, \mathbf{B})$. The analysis of immunological complexity and trajectory identified two data subsets, including observations recorded one day apart (which were assigned to different subsets) and observations collected 9 days apart (which were clustered together, C-E). When time, trajectory, and specific leukocyte cell types were considered, two subsets were distinguished which did not include or included information on antibiotic therapy (the earlier and later subsets, respectively, F-I). Because only the monocyte percentage data displayed subsets orthogonal to one another and showing opposite directionalities, findings supported the hypothesis that ceftriaxone and vancomycin, together, modulated monocytes (F-I).

Figure 3. Earlier discrimination in pneumonia. Ambiguity was documented twice when leukocyte percentages were analyzed over time $(\mathbf{A}, \mathbf{B})$. The analysis of complexity, time, and trajectory revealed two non-overlapping data subsets (C-F) which: (i) discriminated earlier 
(at day 9, when the $\mathrm{N} / \mathrm{L}$ ratio was used $[\mathbf{G}]$, as opposed to day 18 when the $\mathrm{N} \%$ was measured, A), and (ii) indicated that recovery was not initiated by any one antibiotic $(\mathbf{H})$.

Figure 4. Multicellular modulation in an intra-abdominal infection. The analysis that included multicellular complexity, trajectory, time, and antibiotics in space discriminated two data subsets (A-E). In contrast, the analysis of individual cell types did not discriminate (FH). Ceftriaxone and metronidazole modulated not a single cell type but a complex function characterized by the $[\mathrm{L} / \mathrm{M}] /[\mathrm{N} / \mathrm{L}] \operatorname{ratio}(\mathbf{E})$.

Figure 5. Monocyte modulation in tuberculosis. While a multidimensional analysis distinguished two subsets that revealed non-overlapping values (A-D), no pair of leukocytes, when measured as percentages, identified such subsets (E-G). An additional subset was identified when antibiotics were measured, which was associated with isoniazid-related therapy $(\mathbf{H})$. When the trajectory of specific cell types and antibiotics were tested, isoniazidrelated therapy seemed to modulate monocytes (I).

Figure 6. Lymphocyte modulation in multi-morbidity. Ambiguity was expressed as two temporal observations, collected six days apart, that expressed similar values of lymphocyte (L), neutrophil (N) and monocyte (M) percentages (A). However, the combination of space, immunological complexity, trajectory, time and antibiotics distinguished three nonoverlapping data subsets that expressed feedback (a circular pattern, B-E). Amphotericin characterized all data points included in the last subset $(\mathbf{F})$, which modulated lymphocytes but no phagocytes (G-I). 


\section{Figure 1}
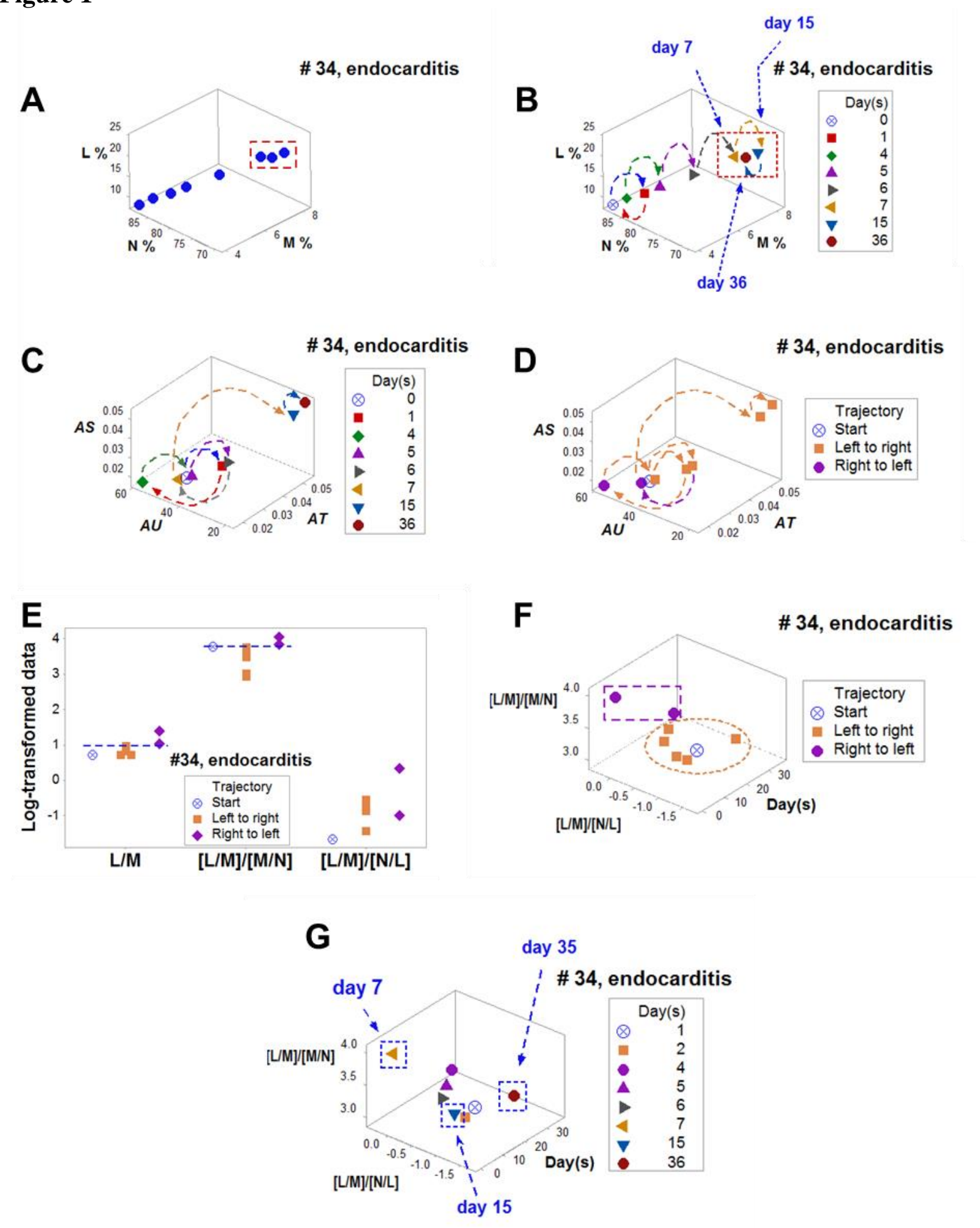
medRxiv preprint doi: https://doi.org/10.1101/2021.01.22.21249954; this version posted January 26, 2021. The copyright holder for this preprint (which was not certified by peer review) is the author/funder, who has granted medRxiv a license to display the preprint in perpetuity.

It is made available under a CC-BY-ND 4.0 International license.

\section{Figure 2}

A

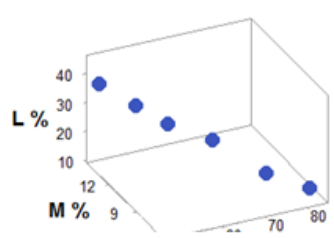

C

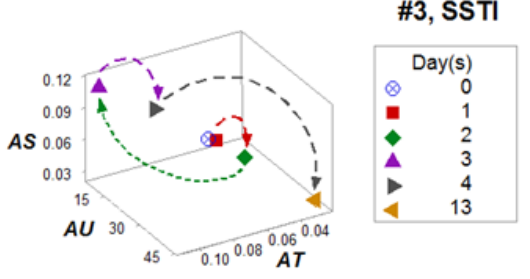

B

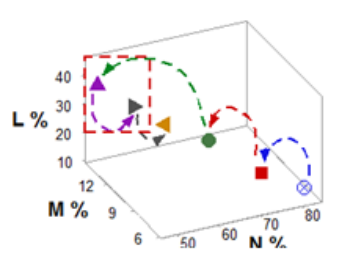

\#3, SSTI

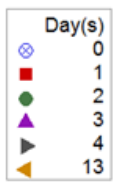

D

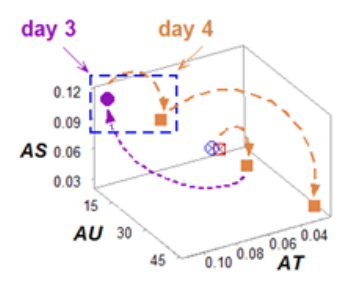

\#3, SSTI

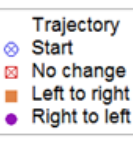

$\mathbf{E}$

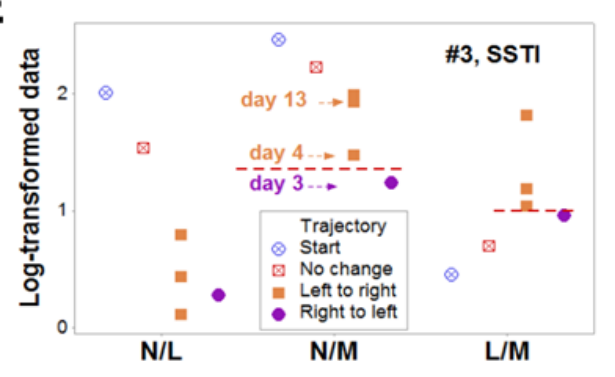

F

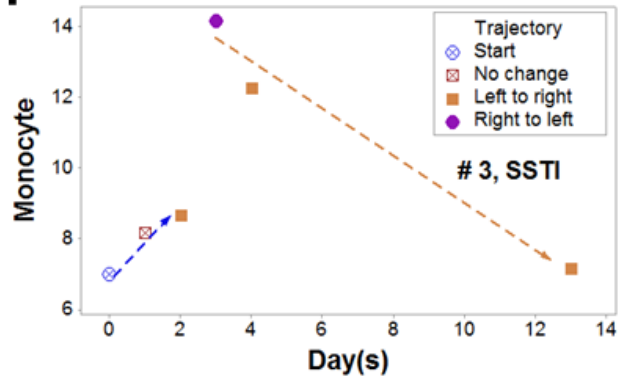

G

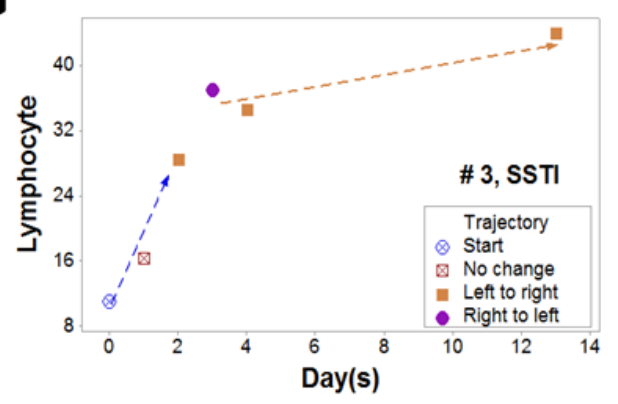

H

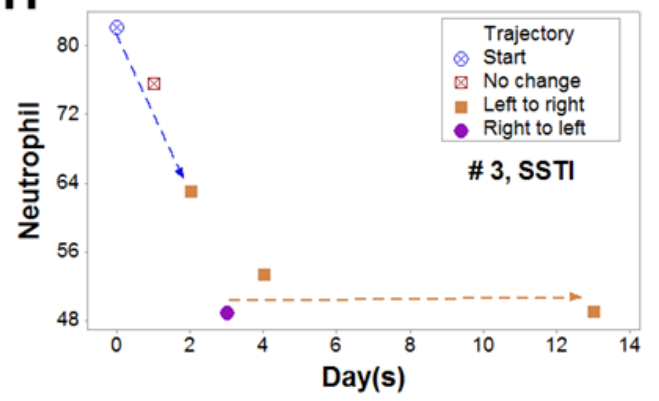

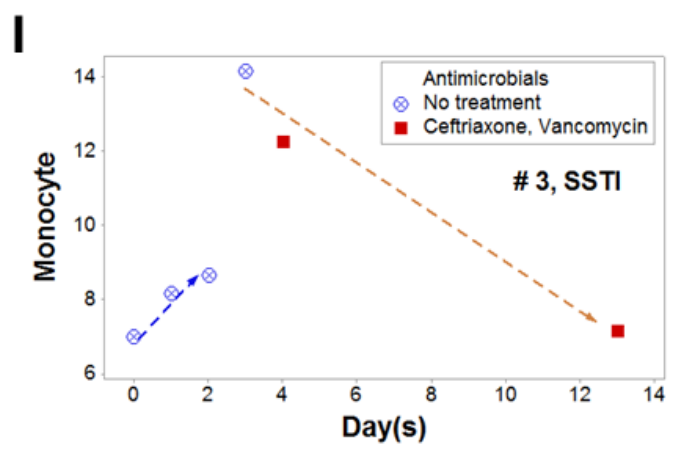


medRxiv preprint doi: https://doi.org/10.1101/2021.01.22.21249954; this version posted January 26, 2021. The copyright holder for this preprint (which was not certified by peer review) is the author/funder, who has granted medRxiv a license to display the preprint in perpetuity. It is made available under a CC-BY-ND 4.0 International license .

\section{Figure 3}

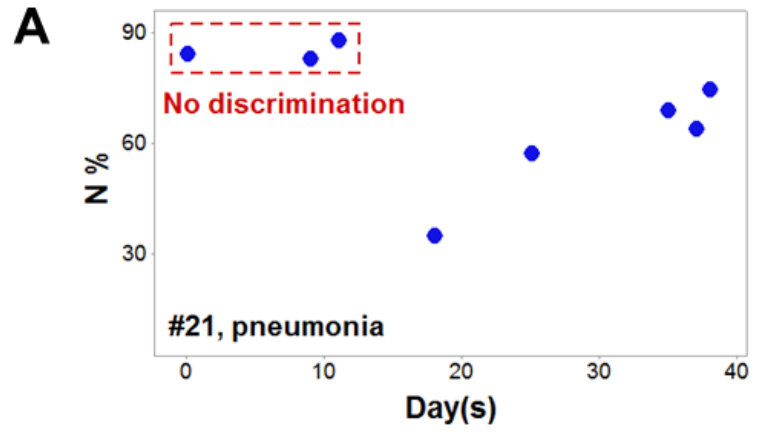

C

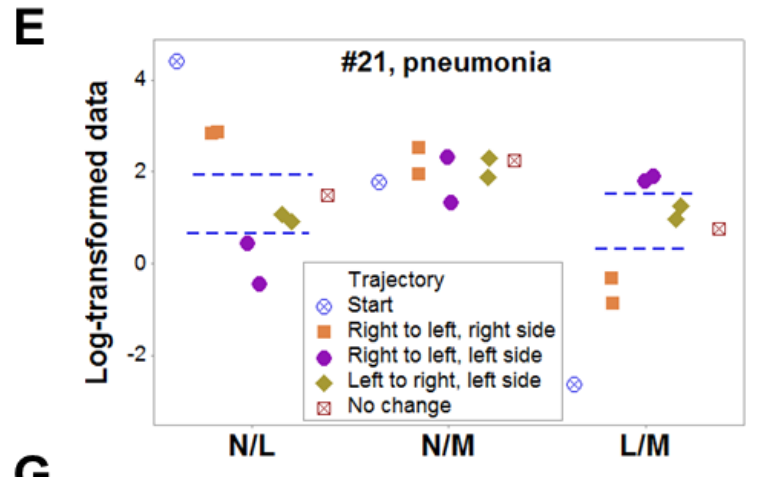

G
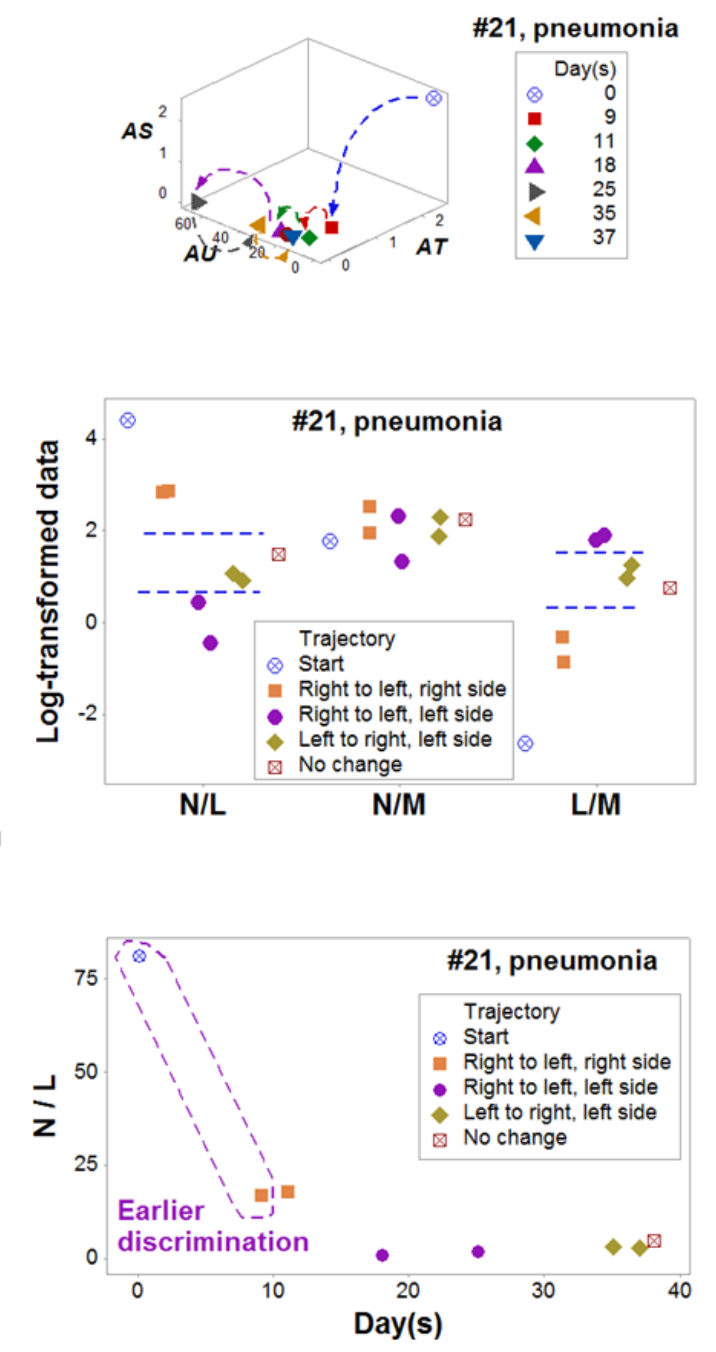

B

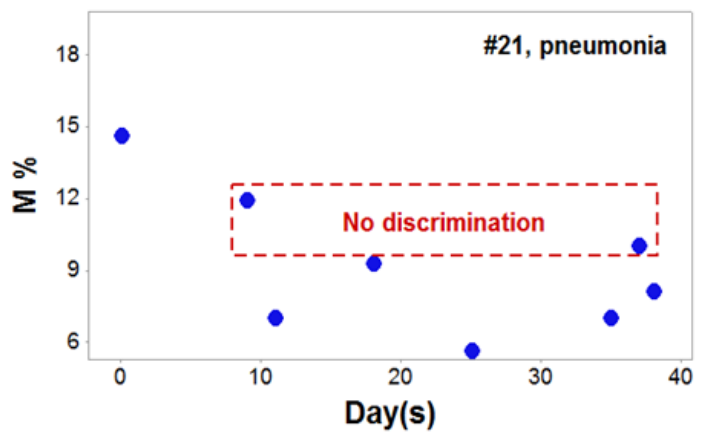

D
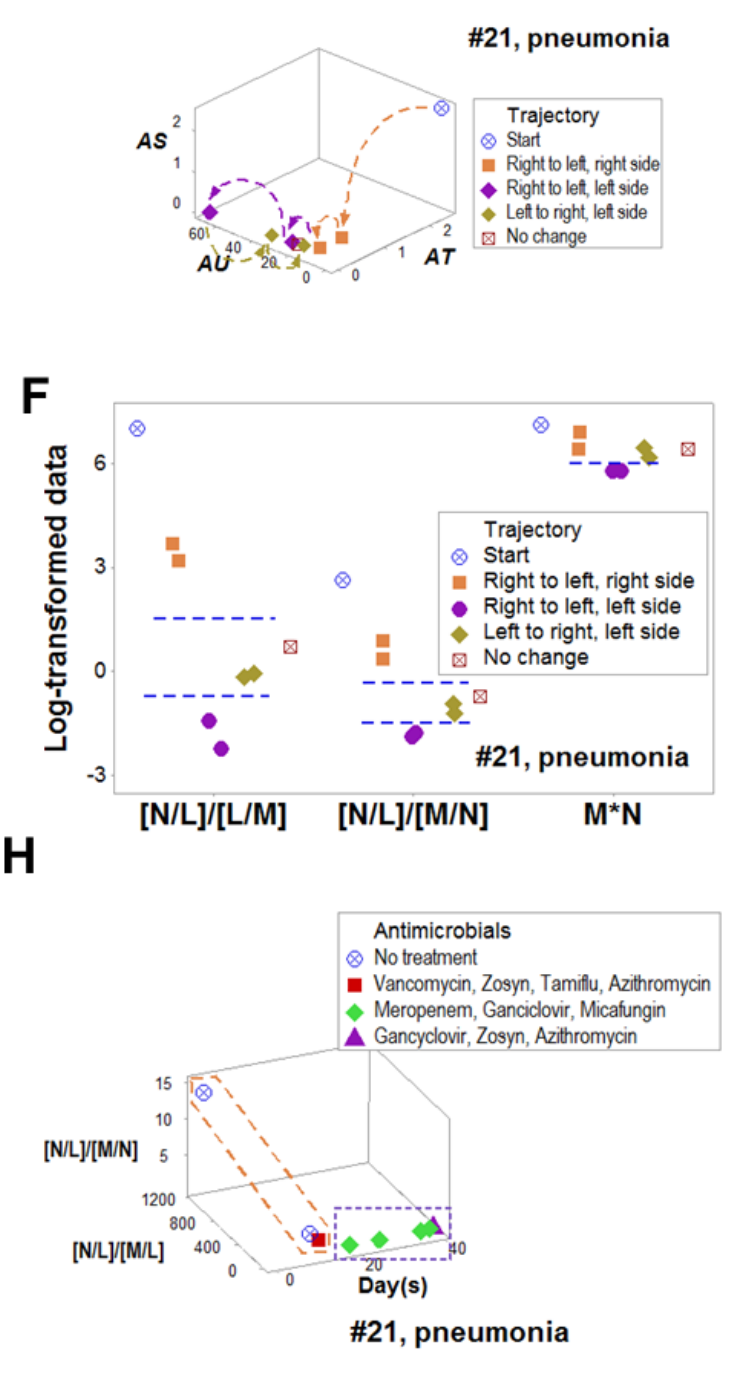
medRxiv preprint doi: https://doi.org/10.1101/2021.01.22.21249954; this version posted January 26, 2021. The copyright holder for this preprint (which was not certified by peer review) is the author/funder, who has granted medRxiv a license to display the preprint in perpetuity. It is made available under a CC-BY-ND 4.0 International license.

\section{Figure 4}
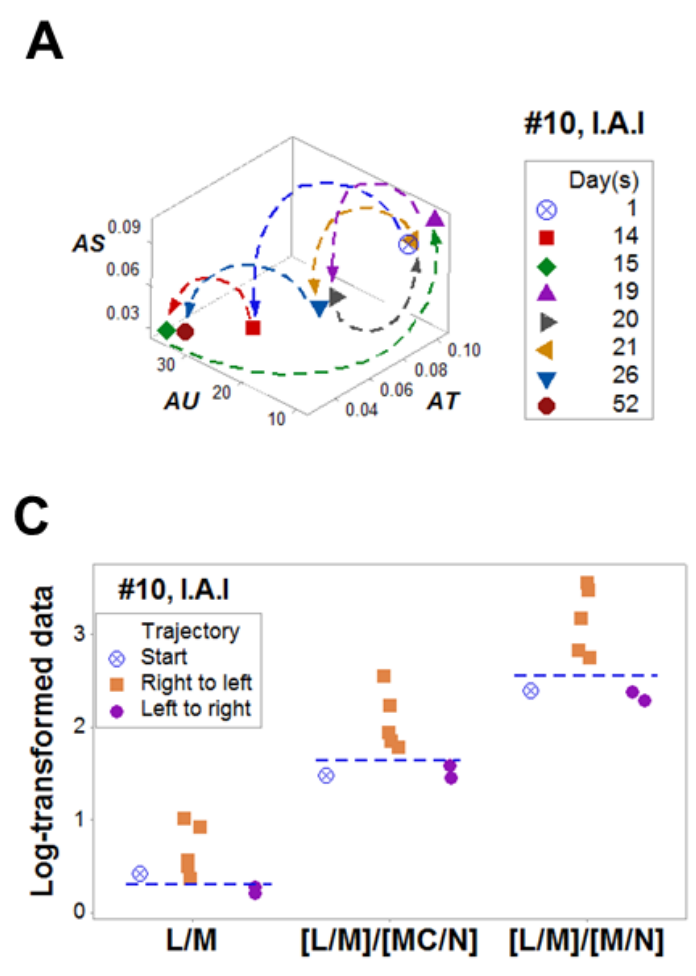

E

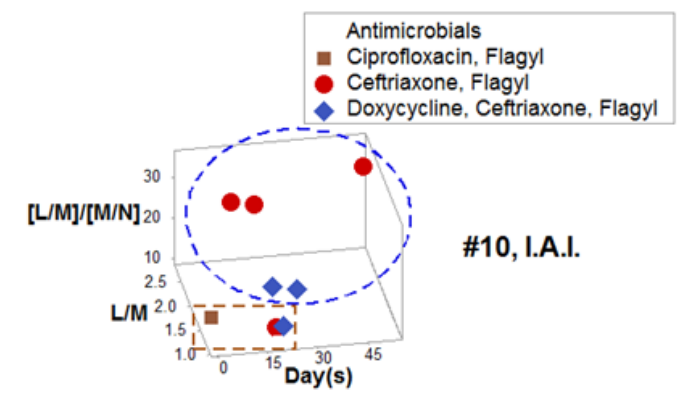

G

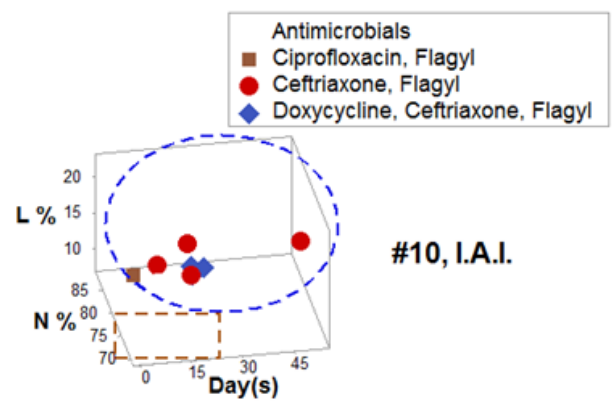

B

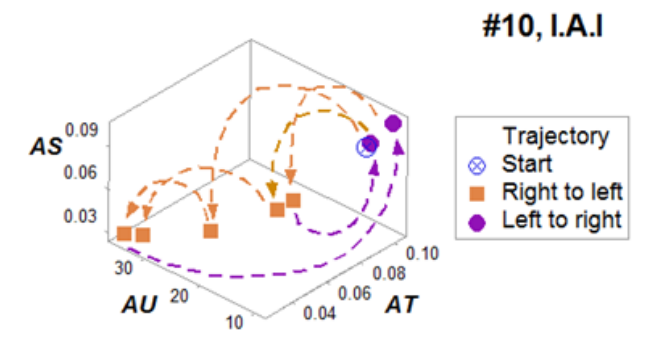

D

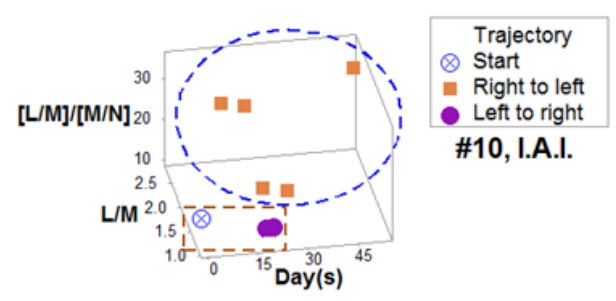

F
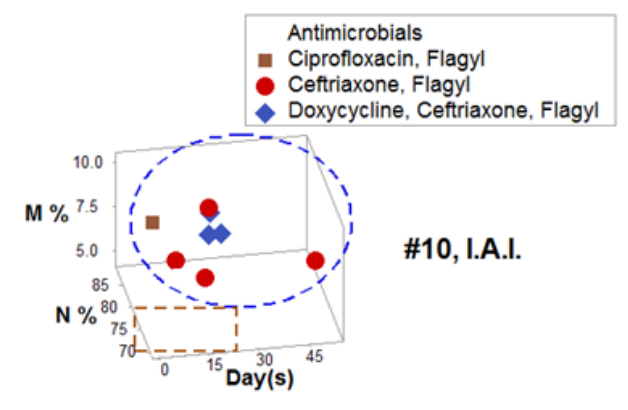

H

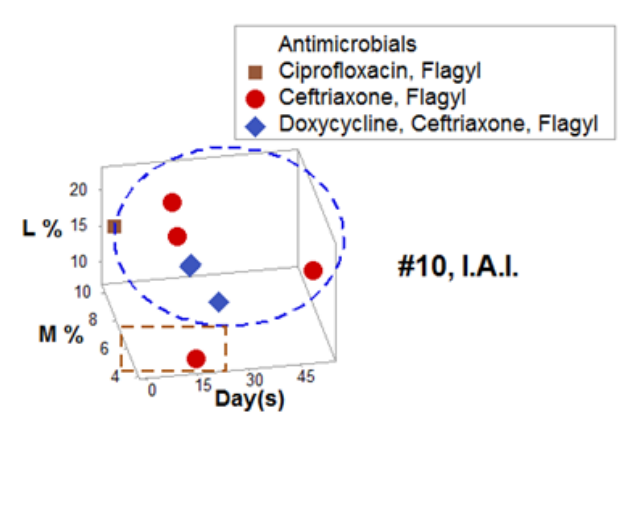


medRxiv preprint doi: https://doi.org/10.1101/2021.01.22.21249954; this version posted January 26, 2021. The copyright holder for this preprint (which was not certified by peer review) is the author/funder, who has granted medRxiv a license to display the preprint in perpetuity.

\section{It is made available under a CC-BY-ND 4.0 International license .}

\section{Figure 5}

\section{A}
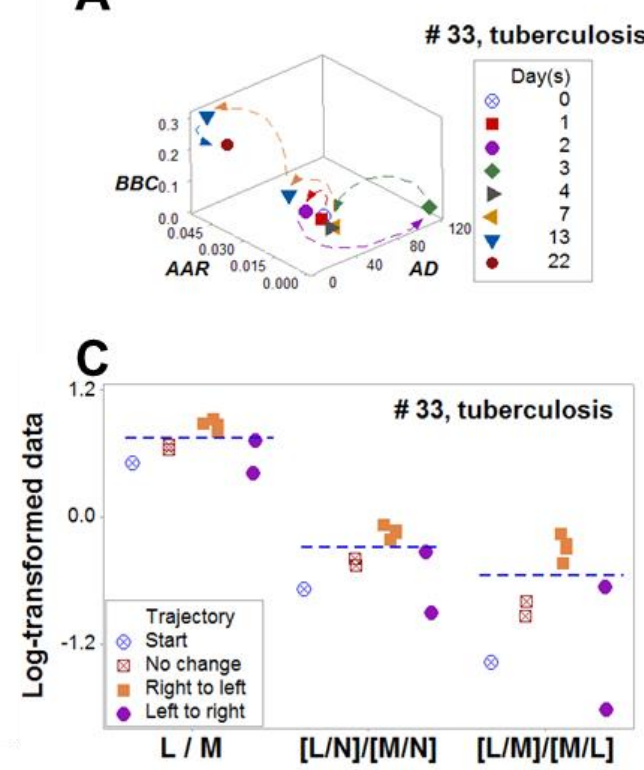

$\mathbf{E}$

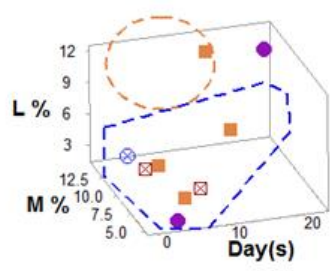

G

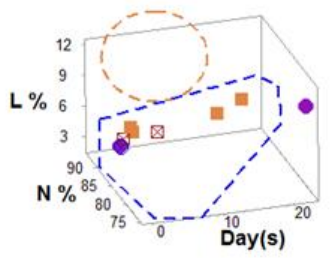

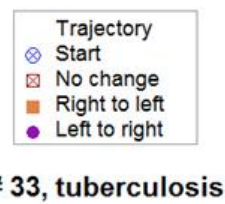

\# 33, tuberculosis

B

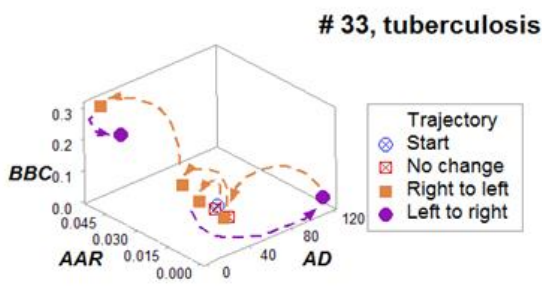

D

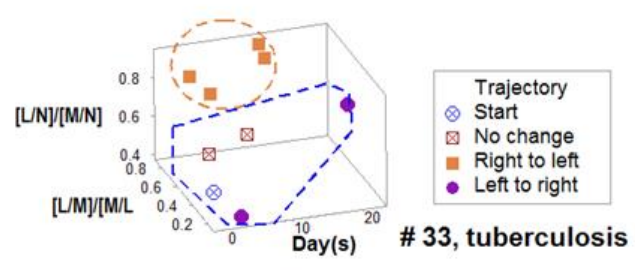

F
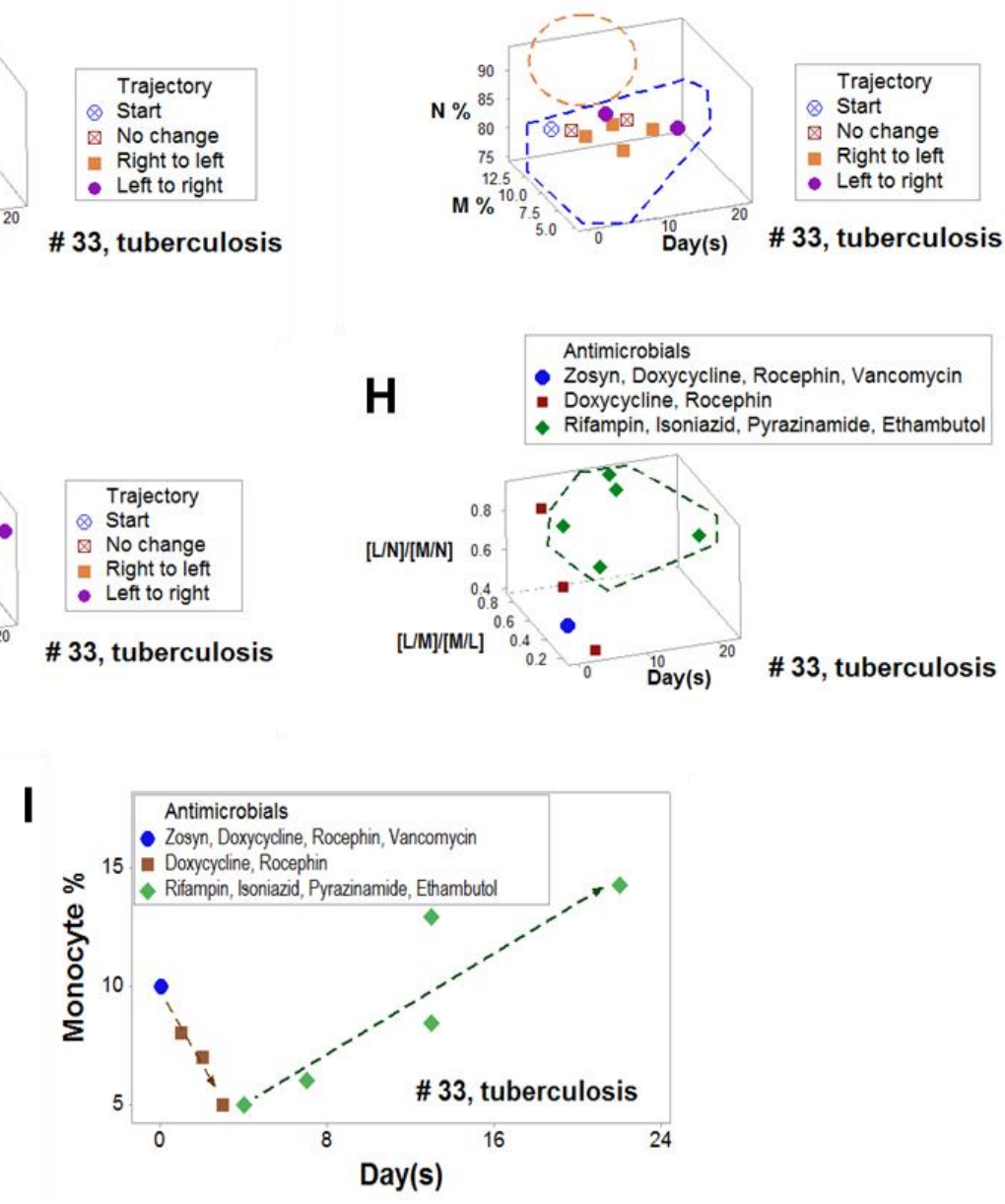
medRxiv preprint doi: https://doi.org/10.1101/2021.01.22.21249954; this version posted January 26, 2021. The copyright holder for this preprint (which was not certified by peer review) is the author/funder, who has granted medRxiv a license to display the preprint in perpetuity.

\section{Figure 6}

\section{A}

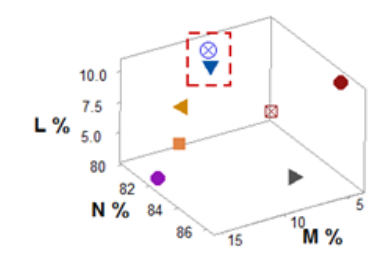

\#18, UTI, meningitis

C

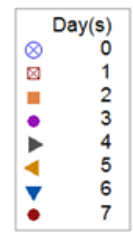

\#18, UTI, meningitis

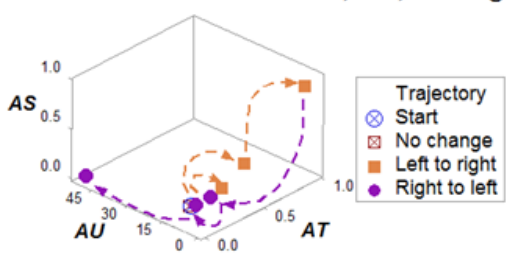

E

\#18, UTI, meningitis

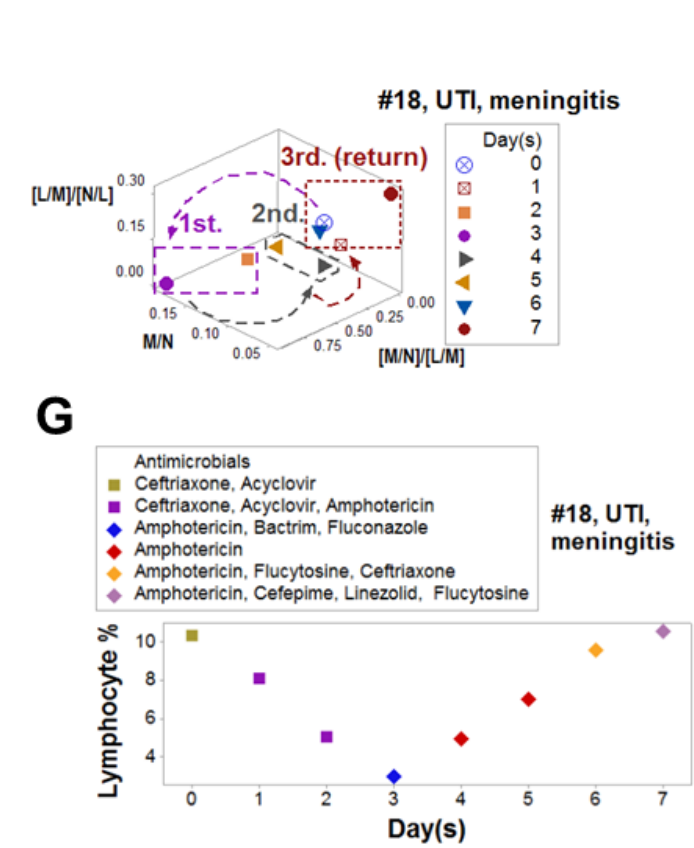

G

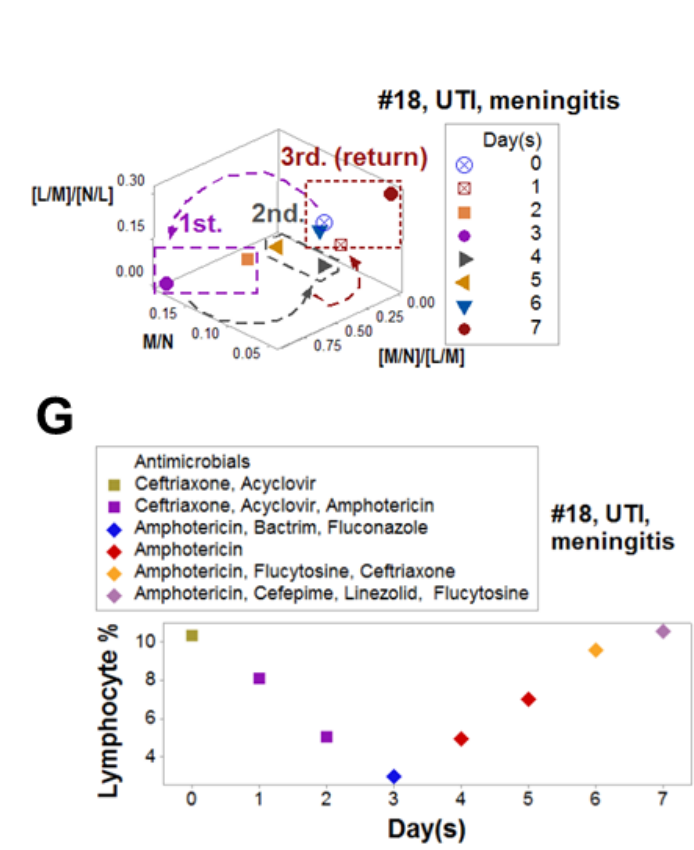

B

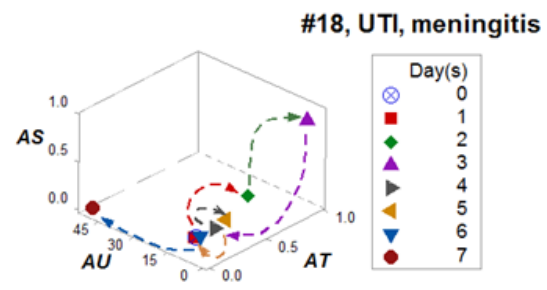

D

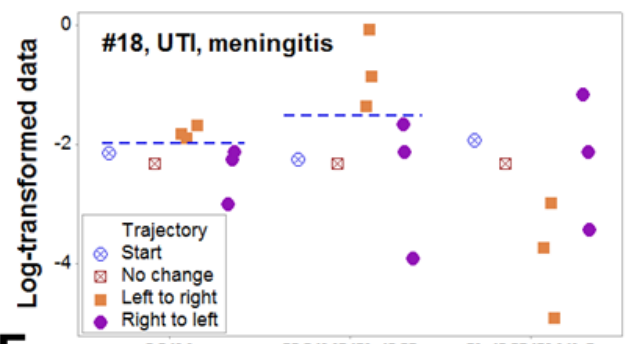

H

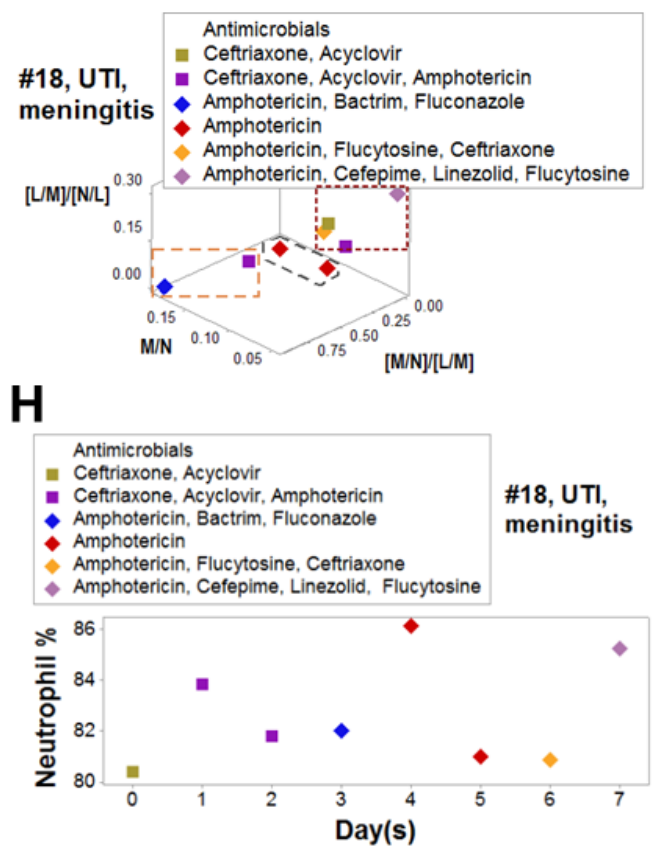

I

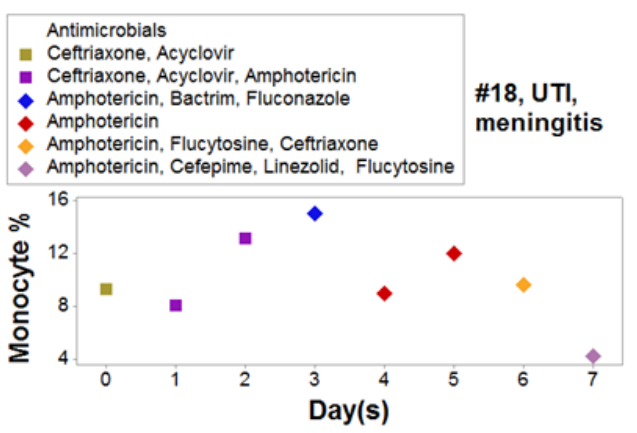




\section{References}

1. Begley CG, Ioannidis JPA. Reproducibility in science - improving the standard for basic and preclinical research. Circ Res 116:116-126, 2015. DOI: 10.1161/CIRCRESAHA.114.303819

2. Amrhein V, Korner-Nievergelt F, Roth T. The earth is flat ( $\mathrm{p}>0$ 0:05): significance thresholds and the crisis of unreplicable research. PeerJ, e3544, 2017. DOI: 10.7717/peerj.3544 2

3. Heng HHQ. The conflict between complex systems and reductionism. JAMA 300:1580-1581, 2008. DOI:10.1001/jama.300.13.1580.

4. Rivas AL, Leitner G, Jankowski MD, Hoogesteijn AL, Iandiorio MJ, Chatzpanagiotou S, Ioannidis A, Blum SE, Piccinini R, Antoniades A, Fazio JC, Apidianakis Y, Fair JM, Van Regenmortel MHV. Nature and consequences of biological reductionism for the immunological study of infectious diseases. Front Immunol 8:612, 2017. DOI:10.3389/fimmu.2017.00612

5. Zeiss CJ, Brayton CF. Immune responses to the real world. Lab Animal 47:13-14, 2018. DOI:10.1038/laban.1384

6. Zeilstra D, Younes YA, Brummer RJ, Kleerebezem M. Perspective: Fundamental Limitations of the Randomized Controlled Trial Method in Nutritional Research: The Example of Probiotics. Adv Nutr 9:561-571, 2018. doi:10.1093/advances/nmy046

7. Hittner JB, Hoogesteijn AL, Fair JM, van Regenmortel MHV, Rivas AL. The Third Cognitive Revolution. EMBO Rep 20, e47647, 2019. DOI:10.15252/embr.201847647

8. Greenhalgh T, Papoutsi C. Studying complexity in health services research: desperately seeking an overdue paradigm shift. BMC Medicine 16:95, 2018. Doi:10.1186/s12916-018-1089-4

9. Wieringa S, Engebretsen E, Heggen K, Greenhalgh T. Rethinking bias and truth in evidence-based health care. $J$ Eval Clin Pract. 24:930-938, 2018. DOI: 10.1111/jep. 13010

10. Greenhalgh T. Of lamp posts, keys, and fabled drunkards: A perspectival tale of 4 guidelines. J Eval Clin Pract. 24:1132-1138, 2018. DOI:10.1111/jep.12925

11. Greenhalgh T, Howick J, Maskrey N. Evidence based medicine: a movement in crisis? BMJ 348: g3725, 2014. DOI:10.1136/bmj.g3725

12. Croft P, Altman DG, Deeks JJ, Dunn KM, Hay AD, Hemingway H, et al. The science of clinical practice: disease diagnosis or patient prognosis? Evidence about "what is likely to happen" should shape clinical practice. BMC Medicine 13:20, 2015. DOI 10.1186/s12916-014-0265-4

13. Rivas AL, Hoogesteijn AL, Antoniades A, Tomazou M, Buranda T, Perkins DJ, Fair JM, Durvasula R, Fasina FO, Tegos GP, van Regenmortel MHV. Assessing the dynamics and complexity of disease pathogenicity using 4-dimensional immunological data. Front Immunol 10:1258, 2019. DOI:10.3389/fimmu.2019.01258

14. $\mathrm{Xu} \mathrm{C}$, Jackson SA. Machine learning and complex biological data. Genome Biol. 20:76, 2019. DOI:10.1186/s13059-019-1689-0

15. Rapacciuolo G, Blois JL. Understanding ecological change across large spatial, temporal and taxonomic scales: integrating data and methods in light of theory. Ecography 42:1247-1266, 2019. DOI:10.1111/ecog.04616

16. Cazaly E, Saad J, Wang W, et al. Making sense of the epigenome using data 
integration approaches. Front. Pharmacol. 10:126, 2019. DOI:

10.3389/fphar.2019.00126

17. Ladau J, Eloe-Fadrosh. EA. Spatial, temporal, and phylogenetic scales of microbial ecology. Trends Microbiol 27, 2019. DOI:10.1016/j.tim.2019.03.003

18. Schork NJ. Time for one-person trials. Nature 520:609-611, 2015. DOI: $10.1038 / 520609 \mathrm{a}$

19. West SA, Cooper GA. Division of labour in microorganisms: an evolutionary perspective. Nat. Rev. Microbiol. 14:716 -723, 2016. DOI: 10.1038/nrmicro.2016.111

20. Bich L, Pradeu T, Moreau J-F. Understanding multicellularity: the functional organization of the intercellular space. Front. Physiol. 10:1170, 2019. DOI: 10.3389/fphys.2019.01170

21. Munguia J, Nizet V. Pharmacological targeting of the host-pathogen interaction: alternatives to classical antibiotics to combat drug-resistant superbugs. Trends Pharmacol Sci. 38: 473-488, 2017. DOI:10.1016/j.tips.2017.02.003

22. Hancock, REW, Nijnik A; Philpott, DJ. Modulating immunity as a therapy for bacterial infections. Nature Rev Microbiol 10: 243-254, 2012. DOI: 10.1038/nrmicro2745

23. Zapater P, González-Navajas JM, Such J, Francés R. Immunomodulating effects of antibiotics used in the prophylaxis of bacterial infections in advanced cirrhosis. World J Gastroenterol 2015; 21(41): 11493-11501. DOI: 10.3748/wjg.v21.i41.11493

24. Wang J, Xia L, Wang R, Cai Y. Linezolid and its immunomodulatory effect: in vitro $\begin{array}{lllll}\text { and in vivo evidence. Front Pharmacol 10:1389, } 2019 . & \end{array}$ DOI:10.3389/fphar.2019.01389

25. Haworth CS, Bilton D, Elborn JS. Long term macrolide maintenance therapy in nonCF bronchiectasis: evidence and questions. Respir Med 108:1397-1408, 2014. DOI:10.1016/j.rmed.2014.09.005

26. Kelly C, Chalmers JD, Crossingham I, Relphl N, Felix LM, Lambert M, Evans DJ, Milan SJ, Spencer S. Macrolide antibiotics for bronchiectasis. Cochran Database Sys Rev 3:CD012406, 2018. DOI:10.1002/14651858.CD012406.pub2

27. Domenech M, Sempere J, de Miguel S and Yuste J (2018) Combination of antibodies and antibiotics as a promising strategy against multidrug-resistant pathogens of the respiratory tract. Front. Immunol. 9:2700. DOI:10.3389/fimmu.2018.02700

28. Rhedin S, Galanis I, Granath F, Ternhag A, Hedlund J, Spindler C, Naucler P. Narrow-spectrum B-lactam monotherapy in hospital treatment of community-acquired pneumonia: a register-based cohort study. Clin Microbiol Infect. 23:247-252, 2017. DOI:10.1016/j.cmi.2016.12.015

29. Marino S, Cilfone NA, Mattila JT, Linderman JJ, Flynn JL, Kirschner DE. Macrophage polarization drives granuloma outcome during Mycobacterium tuberculosis infection. Infect Immun 83:324-338, 2015. DOI:10.1128/IAI.02494-14

30. Tameris MD. Safety and efficacy of MVA85A, a new tuberculosis vaccine, in infants previously vaccinated with BCG: a randomised, placebo-controlled phase $2 \mathrm{~b}$ trial. Lancet 381:1021-1028, 2013. DOI:10.1016/ S0140-6736(13)60177-4

31. Anuforom O, Wallace GR, Piddock LV. The immune response and antibacterial therapy. Med. Microbiol. Immunol. 204:151-159, 2015. DOI:10.1007/s00430-0140355-0015 
32. Yang JH, Bhargava P, McCloskey D, Mao N, Palsson BO, Collins JJ. Antibioticinduced changes to the host metabolic environment inhibit drug efficacy and alter immune function. Cell Host \& Microbe 22:757-765, 2017. DOI: 10.1016/j.chom.2017.10.020

33. Wheat PF. History and development of antimicrobial susceptibility testing methodology. J. Antimicrob. Chemother. $48 \quad$ (Suppl.1),1-4, 2001. DOI:10.1093/jac/48.suppl_1.1

34. Arena F, Viaggi B, Galli L, MD, Rossolini GM. Antibiotic Susceptibility Testing Present and Future. Pediatr Infect Dis J 34:1128-1130, 2015. DOI: 10.1097/INF.0000000000000844 2015.

35. Morales A, Campos M, Juarez JM, Canovas-Segura B, Palacios F, Marin R. A decision support system for antibiotic prescription based on local cumulative antibiograms. J Biomed Inform 84 (2018) 114-122. DOI: 10.1016/j.jbi.2018.07.003

36. Huttner A, Harbarth S, Hope WW, Lipman J, Roberts JA. Therapeutic drug monitoring of the b-lactam antibiotics: what is the evidence and which patients should we be using it for? J Antimicrob Chemother 70:3178-3183, 2015. DOI: 10.1093/jac/dkv201

37. van Regenmortel MHV, Hull DL. In: Promises and limits of reductionism in the biomedical sciences. Chichester, West Sussex, England: Wiley. 2002. DOI:10.1002/0470854189

38. van Regenmortel MHV. Reductionism and complexity in molecular biology. EMBO Rep 5: 1016-1020, 2004. DOI:10.1038/sj.embor.7400284

39. van Regenmortel MHV. Basic research in HIV vaccinology is hampered by reductionist thinking. Front Imm 3:194, 2012. DOI:10.3389/fimmu.2012.00194

40. Iandiorio MJ, Fair JM, Chatzipanagiotou S, Ioannidis A, Trikka-Graphakos E, Charalampaki N, Sereti C, Tegos GP, Hoogesteijn AL, Rivas AL. Preventing data ambiguity in infectious diseases with four-dimensional, earlier, personalized, in vivo evaluations. PLoS ONE 11: e0159001, 2016. DOI:10.1371/journal.pone.0159001

41. Henly SJ, Wyman JF, Findorff MJ. Health and illness over time: the trajectory perspective in nursing science. Nursing Res 60: S5-S14, Suppl 3, 2011. DOI: 10.1097/NNR.0b013e318216dfd3

42. Pham T, Tran T, Phung D, Venkatesh S. Predicting healthcare trajectories from medical records: a deep learning approach. J Biomed Inform 69: 218-229, 2017. DOI: 10.1016/j.jbi.2017.04.001

43. Zemedikun DT, Gray LJ, Khunti K, Davies MJ, Dhalwani NN. Patterns of multimorbidity in middle-aged and older adults: an analysis of the UK Biobank Data. Mayo Clinic Proc 93:857-866, 2018. DOI: 10.1016/j.mayocp.2018.02.012

44. Rivas AL, Hoogesteyn AL, Piccinini R. Beyond numbers: the informative patterns of immuno-staphylococcal dynamics. Current Pharmaceutical Design 21:2122-2130, 2015. DOI:10.1371/journal.pone.01236742015

45. Slipczuk L, Codolosa JN, Davila CD, Romero-Corral A, Yun J, et al. Infective endocarditis epidemiology over five decades: a systematic review. PLoS ONE 8(12): e82665. 2013. DOI:10.1371/journal.pone.0082665

46. Lozano R, Naghavi M, Foreman K, Lim S, Shibuya K, Aboyans V, et al. Global and regional mortality from 235 causes of death for 20 age groups in 1990 and 2010: a 
medRxiv preprint doi: https://doi.org/10.1101/2021.01.22.21249954; this version posted January 26, 2021. The copyright holder for this preprint (which was not certified by peer review) is the author/funder, who has granted medRxiv a license to display the preprint in perpetuity.

It is made available under a CC-BY-ND 4.0 International license .

systematic analysis for the global burden of disease study 2010. Lancet 380:20952128, 2012. DOI:10.1016/S0140-6736(12)61728-0

47. Ramirez JA, Wiemken TL, Peyrani P, Arnold FW, Kelley R, Mattingly WA, Nakamatsu R, Pena S, Guinn BE, et al. Adults hospitalized with pneumonia in the United States: incidence, epidemiology, and mortality. Clin Inf Dis 65: 1806 -1812, 2018. DOI:10.1093/cid/cix647

48. De Waele J, Lipman J, Sakr Y, Marshall JC, Vanhems P, et al. Abdominal infections in the intensive care unit: characteristics, treatment and determinants of outcome. BMC Infect Dis 14:420, 2014. DOI:10.1186/1471-2334-14-420

49. Kaye KS, Petty LA, Shorr AF, Zilberberg MD. Current epidemiology, etiology, and burden of acute skin infections in the United States. Clin Infect Dis 68 (Suppl 3): S193-S199, 2019. DOI:10.1093/cid/ciy576

50. Khorsan R, Crawford C. How to assess the external validity and model validity of therapeutic trials: a conceptual approach to systematic review methodology. Evid Based Complement Altern Med 694804, 2014. DOI:10.1155/2014/694804

51. Wynn TA, Chawla A, Pollard JW (2013) Macrophage biology in development, homeostasis and disease. Nature 496:445-454. DOI:10.1038/nature12034

52. Miller EG, Viola PA. Ambiguity and Constraint in Mathematical Expression. Recognition. In: Proceedings of the 15th National Conference on Artificial Intelligence, pp. 784-791. Madison (1998).

53. Le AD, Indurkhya $\mathrm{B}$, Nakagawa $\mathrm{M}$. Pattern generation strategies for improving recognition of Handwritten Mathematical Expressions. Pattern Recognit Lett 128:255262, 2019. DOI:10.1016/j.patrec.2019.09.002

54. Qu Z, Garfinkel A, Weiss JN, Nivala M. Multi-scale modeling in biology: how to bridge the gaps between scales. Prog. Biophy. Mol. Biol. 107:21-31, 2011. DOI: 10.1016/j.pbiomolbio.2011.06.004

55. Green S, Batterman R. Biology meets physics: Reductionism and multi-scale modeling of morphogenesis Stud. Hist. Philos. Biol. Biomed. Sci. 61:20-34, 2017. DOI:10.1016/j.shpsc.2016.12.003

56. Bzdok D. Classical statistics and statistical learning in Imaging Neuroscience. Front. Neurosci. 11:543, 2017. DOI:10.3389/fnins.2017.00543

57. Lee CH, Yoon H-J. 2017. Medical big data: promise and challenges. Kidney Res Clin Pract 36:3-11. DOI:10.23876/j.krcp.2017.36.1.3

58. Horiguchi H, Loftus TJ, Hawkins RB, Raymond SL, Stortz JA, Hollen MK, et al. Innate immunity in the persistent inflammation, immunosuppression, and catabolism syndrome and its implications for therapy. Front. Immunol. 9:595, 2018. DOI:10.3389/fimmu.2018.00595

59. Zaidan MA, Wraith D, Boor BE, Hussein. T. Bayesian proxy modelling for estimating black carbon concentrations using white-box and black-box models. App Sci-Basel 9: 4976, 2019. DOI:10.3390/app9224976

60. Handelman GS, Kok HK, Chandra RV, Razavi AH, Huang S, Brooks M, et al. Peering into the black box of artificial intelligence: evaluation metrics of machine learning methods. AJR 212:38-43, 2019. DOI: 10.2214/AJR.18.20224

61. Salisbury C, Man MS, Bower P, Guthrie B, Chaplin K, Gaunt DM et al. Management of multimorbidity using a patient-centred care model: a pragmatic cluster-randomised 
medRxiv preprint doi: https://doi.org/10.1101/2021.01.22.21249954; this version posted January 26, 2021. The copyright holder for this preprint (which was not certified by peer review) is the author/funder, who has granted medRxiv a license to display the preprint in perpetuity. It is made available under a CC-BY-ND 4.0 International license .

trial of the 3D approach. Lancet 392:41-50, 2018. DOI:10.1016/S01406736(18)31308-4

62. Rothwell PM. Factors that can affect the external validity of randomised controlled trials. PLoS Clin Trials 1:e9, 2006. DOI:10.1371/journal.pctr. 0010009

63. Olson JE, Takahashi PY, St Sauver JM. Understanding the Patterns of Multimorbidity. Mayo Clinic Proc 93: 824-825, 2018. DOI:10.1016/j.mayocp.2018.05.016

64. Salive ME. Multimorbidity in older adults. Epidemiol Rev 35:75-83, 2013. DOI: 10.1093/epirev/mxs009

65. Gupta S, Vishnu Prasad Shenoy VP, Bairy I, Srinivasa H, Mukhopadhyay C. Diabetes mellitus and HIV as co-morbidities in tuberculosis patients of rural south India. $J$. Infect. Public Health 4:140 - 144, 2011. DOI:10.1016/j.jiph.2011.03.005

66. Sembiah S, Nagar V, Gour D, Pal DK, Mitra A, Burman J. Diabetes in tuberculosis patients: an emerging public health concern and the determinants and impact on treatment outcome. J Fam Community Med 27:91-96, 2020. DOI: 10.4103/jfcm.JFCM_296_19

67. Kwan CK, Ernst JD. HIV and tuberculosis: a deadly human syndemic. Clin Microb Rev 24:351-376, 2011. DOI:10.1128/CMR.00042-10

68. Fuller J. Rationality and the generalization of randomized controlled trial evidence. $J$ Eval Clin Pract 19:644-647, 2013. DOI:10.1111/jep.12021

69. Zeilstra D, Youne JA, Brummer RJ, Kleerebeze M. Fundamental limitations of the randomized controlled trial method in nutritional research: the example of probiotics. Adv Nutr 9:561-571, 2018. DOI:10.1093/advances/nmy046

70. Athlin S, Lidman C, Lundqvist A, Naucler P, Nilsson AC, Spindler C, et al. Management of community acquired pneumonia in immunocompetent adults: updated Swedish guidelines. Infect Dis 50:247-272, 2017.

DOI:10.1080/23744235.2017.1399316

71. Corrales-Medina VF, Musher DM. Immunomodulatory agents in the treatment of community-acquired pneumonia: A systematic review. J Infection 63:187-199, 2011. DOI:10.1016/j.jinf.2011.06.009

72. Prabowo SA, Smith SG, Seifert K, Fletcher HA. Impact of individual-level factors on ex vivo mycobacterial growth inhibition: associations of immune cell phenotype, cytomegalovirus-specific response and sex with immunity following BCG vaccination in humans. Tuberculosis 119:101876, 2019. DOI:10.1016/j.tube.2019.101876

73. Joosten SA, van Meijgaarden KE, Arend SM, Prins C, Oftung F, Korsvold GE, et al. Kik SV. Mycobacterial growth inhibition is associated with trained innate immunity. $J$ Clin Investig 128:1837-1851, 2018. DOI:10.1172/JCI97508

74. Ezraty B, Barras F. The 'liaisons dangereuses' between iron and antibiotics. FEMS Microbiol Rev 40:418-435, 2016. DOI:10.1093/femsre/fuw004

75. Kopinč R, Lapanje A. Antibiotic susceptibility profile of Mycobacterium avium subspecies hominissuis is altered in low-iron conditions. J Antimicrob Chemother 67:2903-2907, 2012. DOI:10.1093/jac/dks313

76. Certain LK, Way JC, Pezone MJ, Collins JJ. Using engineered bacteria to characterize infection dynamics and antibiotic effects in vivo. Cell Host \& Microbe 22:263-268, 2017. DOI:10.1016/j.chom.2017.08.001 
77. Stokes JM, Gutierrez A, Lopatkin AJ, Andrews IW, French S, Matic I, Brown ED, Collins JJ. A multiplexable assay for screening antibiotic lethality against drugtolerant bacteria. Nature Meth 16:303-306, 2019. DOI:10.1038/s41592-019-0333-y

78. Aguinagalde L, Corsini B, Domenech A, Domenech M, Cámara J, Ardanuy C, et al. Emergence of amoxicillin-resistant variants of spain9V-ST156 pneumococci expressing serotype $11 \mathrm{~A}$ correlates with their ability to evade the host immune response. PLoS ONE 10(9): e0137565, 2015. DOI:10.1371/journal.pone.0137565

79. Jiang JH, Bhuiyan MS, Shen HH, Cameron DR, Rupasinghe TWT, CWu CM et al. Antibiotic resistance and host immune evasion in Staphylococcus aureus mediated by a metabolic adaptation. Proc Nat Acad Sci of the USA 116: 3722-3727, 2019. DOI: 10.1073/pnas.1812066116

80. van Belkum A, Bachmann TT, Ludke G, Lisby JG, Kahlmeter G, Mohess A et al. Developmental roadmap for antimicrobial susceptibility testing systems. Nature Rev 17:53-62, 2019. DOI:10.1038/s41579-018-0098-9

81. Markowitz MA, Monti GK, Kim JH, Haake DA. Rapid diagnostic testing in the management of urinary tract infection: potentials and limitations. Diagn Microbiol Infect Dis 94:371-377, 2019. DOI:10.1016/j.diagmicrobio.2019.02.019

82. Scriven JE, Tenforde MW, Levitz SM, Jarvis JN. (2017) Modulating host immune responses to fight invasive fungal infections. Curr Opin Microbiol 40:95-103, 2017. DOI:10.1016/j.mib.2017.10.018

83. Mukherjee AK, Gupta G, Bhattacharjee S, Guha SK, Majumder S, Adhikari A, et al. Amphotericin B regulates the host immune response in visceral leishmaniasis: Reciprocal regulation of protein kinase C isoforms. J Infection 61:173-184, 2010. DOI: $10.1016 /$ j.jinf.2010.05.003

84. Rossato L, Loreto ES, Venturini TP, Azevedo MI, Weiblen C, Botton SA, et al. In vitro interaction of antifungal and antibacterial drugs against Cryptococcus neoformans var. grubii before and after capsular induction. Med Mycol 53:885-889, 2015. DOI:10.1093/mmy/myv059

85. Lu M, Yang X, Yu C, Gong Y, Yuan L, Hao L, Sun S. Linezolid in combination with azoles induced synergistic effects against Candida albicans and protected Galleria mellonella against experimental candidiasis. Front. Microbiol. 9:3142, 2019. DOI:10.3389/fmicb.2018.03142

86. Hahn J, Choi JH, Chang MJ. Pharmacokinetic changes of antibiotic, antiviral, antituberculosis and antifungal agents during extracorporeal membrane oxygenation in critically ill adult patients. J Clin Pharm Ther. 42:661-671, 2017. DOI: 10.1111/jcpt. 12636

87. Gao CH, Yu LS, Zeng S, Huang YW, Zhou Q. Personalized therapeutics for levofloxacin: a focus on pharmacokinetic concerns. Ther. Clin. Risk Manag. 10: 217227. DOI:10.2147/TCRM.S59079 